\title{
QUANTIFICATION OF POSTURAL SWAY IN NORMALS AND PATIENTS WITH CEREBELLAR DISEASES ${ }^{1}$
}

\author{
H.C. DIENER, J. DICHGANS, M. BACHER and B. GOMPF \\ Neurologische Universitätsklinik, Abteilung für Allgemeine Neurologie, Liebermeisterstrasse 18-20, D-7400 Tübingen (F.R.G.)
}

(Accepted for publication: July 14, 1983)

This paper compares data from normals and 5 groups of cerebellar patients collected in an attempt to quantify and characterize their postural sway while standing erect. It extends and supplements earlier work by Dichgans et al. (1976) and Mauritz et al. (1979). The results largely confirm those of the previous authors, describing patterns of sway abnormality that are specific to a given localization of the disease within the cerebellum. New is the differentiation of spinal ataxia in Friedreich's ataxia from anterior lobe atrophies and vestibulo-spinal cerebellar diseases. This study also gives a statistical analysis of the diagnostic importance of single sway parameters.

The 5 patient groups represent the most common localizations of diseases causing cerebellar symptoms: (1) Friedreich's disease, which is prototypical for a disorder of spino-cerebellar afferents, (2) atrophy of the anterior cerebellar lobe, the spino-cerebellum, to which spino-cerebellar afferents mainly project, (3) the vestibulo-cerebellum forming the lower vermis, (4) the cerebellar hemispheres, and (5) diffuse cerebellar atrophies. The pattern of recorded abnormalities has been evaluated as to the significance of every pathological result for localizing the causal disease. As a consequence of this, posturography is now a valuable tool in clinical diagnosis and quantitative documentation of postural ataxia for follow-up studies.

\footnotetext{
${ }^{1}$ Supported by the Deutsche Forschungsgemeinscahft (Di $278 / 1-1)$
}

\section{Methods}

\section{Apparatus}

Subjects stood on a force measuring platform. With this, strain gauges at the four corners of the platform measured the displacement of the center of foot pressure (CFP) in the antero-posterior and lateral directions. Antero-posterior sway in our experimental condition was computed from the difference between the front and back strain gauges. The lateral sway was computed in an analog manner from the two right and left force transducers. The influence of the subject's weight was electronically compensated.

\section{Sway parameters}

The antero-posterior and lateral CFP components were digitalized and, after multiplexing (PCM, $f=263 \mathrm{~Hz}$, Kayser K 11 80-20), recorded on tape. On-line computations were done by use of a computer (IN 110). The computer program used a sampling interval of $25 \mathrm{msec}$ and a total sampling duration of $25 \mathrm{sec}$. Since it was impossible to place different subjects in exactly identical positions on the platform, the first step was a normalization procedure. For this purpose the mean from all antero-posterior and lateral values was calculated and taken as the zero point from which the CFP deviated. The sway path (SP) travelled by the CFP on the platform was calculated as in our earlier study (Hufschmidt et al. 1980). The sway area covered by the sway path of the CFP within $25 \mathrm{sec}$ was computed as

$$
\mathrm{SA}=\frac{1}{2} \sum_{i=1}^{\mathbf{n}-1} I \mathrm{x}_{i+1} \mathrm{y}_{i}-\mathrm{x}_{i} \mathrm{y}_{i+1} \mathrm{I}
$$


$\mathrm{n}=$ number of sample points, $\mathrm{x}=$ antero-posterior sway direction and $y=$ lateral sway direction.

The amount of visual stabilization was estimated by the 'Romberg quotient' of the sway path and sway area (SP or SA with eyes closed divided by SP or SA with eyes open (Van Parys and Njiokiktjien 1976).

We also computed a sway direction histogram of the CFP. For this purpose the full circle of possible sway directions was divided into 24 intervals of $15^{\circ}$ each. The single vectors of the displacement of the CFP within each sampling interval were sorted according to their directions and summed up. Straightforward was defined as zero.

The amplitude of body sway in the antero-posterior direction (AP) was calculated as the sum of the 6 direction vectors pointing in the AP direction. The amplitude in the lateral direction (LAT) was calculated in the same manner. The quotient AP : LAT indicates the predominance of anteroposterior body sway. Sway path and sway direction histograms from each subject were depicted on a storage oscilloscope and documented by way of a hard copy unit (Fig. 1).

Simultaneously the displacements of the CFP in the antero-posterior and lateral direction were fed into an on-line Fourier analyser. The total duration of sampling was $40 \mathrm{sec}$. The span of frequencies analysed ranged from 0.01 to $10 \mathrm{~Hz}(0.025 \mathrm{~Hz}$ steps). The sum of the root mean squares calculated from the power spectrum between 0.01 and $10 \mathrm{~Hz}$ served as an additional measure of the amount of postural sway. The peak amplitude within the Fourier spectrum, as identified on the oscilloscope, and its frequency and amplitude were plotted together with the root mean squares on a digital X-Y plotter.

\section{Procedure}

Subjects were placed on the platform with their feet parallel $4 \mathrm{~cm}$ apart. They were instructed to stand as quietly as possible with their arms folded in front of the chest. Intervals of $1 \mathrm{~min}$ each were recorded with eyes open and closed.

\section{Normal subjects}

Twenty healthy subjects (15 men, 5 women) aged between 20 and 60 years constituted the

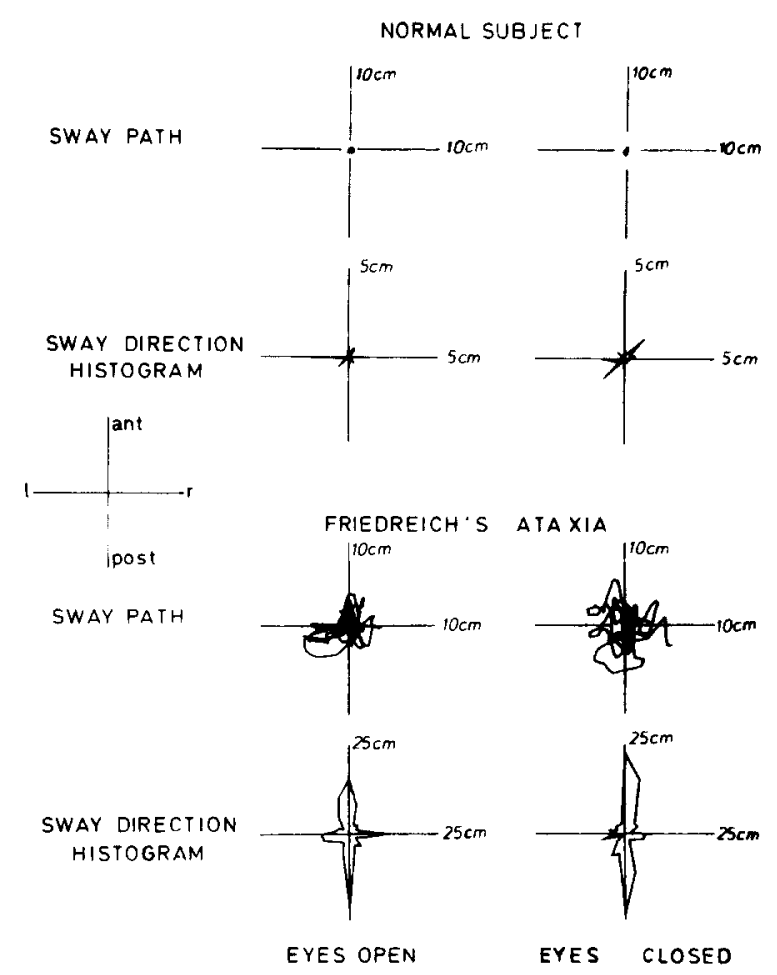

Fig. 1. Sway path and sway area from a normal subject and a patient with Friedreich's ataxia. Note different scalings in the records from the patient.

normal population. The means and standard deviations were calculated from all sway parameters (including root mean squares). The mean +2 S.D. was defined as the upper limit of normality.

\section{Patients}

We examined 41 patients in whom it was possible to define from morphological (CT, surgery) or clinical data the localization of the cerebellar disturbance. The patients were classified into one of the following 5 groups:

(a) Eight patients with Friedreich's ataxia (FRIED) were representative of a disorder affecting mainly the afferents to the cerebellum, mediated by the spino-cerebellar tracts. Signs of involvement of the posterior columns (loss of vibration sense and position sense) were observed in all of them. Computerized tomography showed intact cerebellar structures without atrophy in all of these patients.

(b) Six patients had an isolated lesion of the 
lower cerebellar vermis, the vestibulo-cerebellum (VERMIS). Two of them had a tumor (medulloblastoma, astrocytoma), two a bleed from an angioblastoma. One patient had an aplasia of the vermis. In all of them the vermal lesion was verified by CT and surgery. The anterior lobe and the hemispheres of the cerebellum were not or only little affected. The remaining patient suffered from a Hallgreen syndrome (retinitis pigmentosa, deafness, vestibulo-cerebellar ataxia).

(c) Eleven patients suffered from a late cortical atrophy of the anterior lobe (ANT. LOBE) a disease which can be observed in chronic alcoholics with a nutritional deficiency (Marie et al. 1922; Victor et al. 1959; Mancall 1975; Adams 1976). Polyneuropathy was either absent or moderate. Computerized tomography of the 10 men and 1 woman showed, to a varying degree, a generalized atrophy of the brain with predominance in the vermal and anterior lobe region of the cerebellum.

(d) Seven patients suffered from diseases which were mainly localized in the cerebellar hemispheres (HEMISPH). Three of them had bilateral ischemic lesions. In the four remaining ones, exhibiting ataxia and dysmetria predominantly of the arms and less of the legs, the cause of the cerebellar disease was unknown.

(e) Nine patients had a cerebellar disease which, according to clinical testing and CT, may have affected all parts of the cerebellum (DIFFUSE). Three of them suffered from chronic intoxication (two bromide, one diphenylhydantoin), five suffered from a heredoataxia (Gerstman-Sträussler (1), familial spastic ataxia (2), olivo-cerebellar degeneration of Holmes (2)); in one patient the cause of the cerebellar affection could not be classified.

\section{Results}

\section{(a) Normal subjects}

The sway path during the sample period of 25 sec increased by about $50 \%$ with closed eyes as compared to open eyes (Table I). A similar increase was documented by computing the sway area and the Romberg quotient. The antero-posterior sway was invariably greater than sway in the lateral dimension with and without the visual con- tribution to postural stabilization. The means of individual antero-posterior/lateral quotients again indicated that the increase of sway path and sway area with eye closure was mainly due to an increase in the antero-posterior sway components.

\section{(b) Patients with cerebellar diseases}

Table 1 shows the frequency of pathological results ( $>$ mean +2 S.D.) in the different groups of cerebellar diseases for the 12 parameters. The mean percentage of pathological results amounted to $73.9 \%$ for the patients with atrophy of the anterior lobe. Patients with diffuse cerebellar lesions $(63.9 \%)$ and Friedreich's ataxia (58.3\%) followed. Patients with lower vermal lesions (48.6\%) were more unstable than those with hemispheral cerebellar lesions $(32.2 \%)$. The most effective parameters to detect postural instability were sway path, sway area, and the antero-posterior component of sway (AP), when the stabilizing effect of vision was suppressed by eye closure. Using these 3 parameters $77-86 \%$ of all patients showed pathological results (Fig. 2). The least effective parameters were the registration of the lateral components of sway with open eyes and the quotient of antero-posterior and lateral sway. The particular importance of visual stabilization of posture in patients with late atrophy of the anterior lobe and those with Friedreich's ataxia was illustrated by the frequency of a pathological Romberg quotient

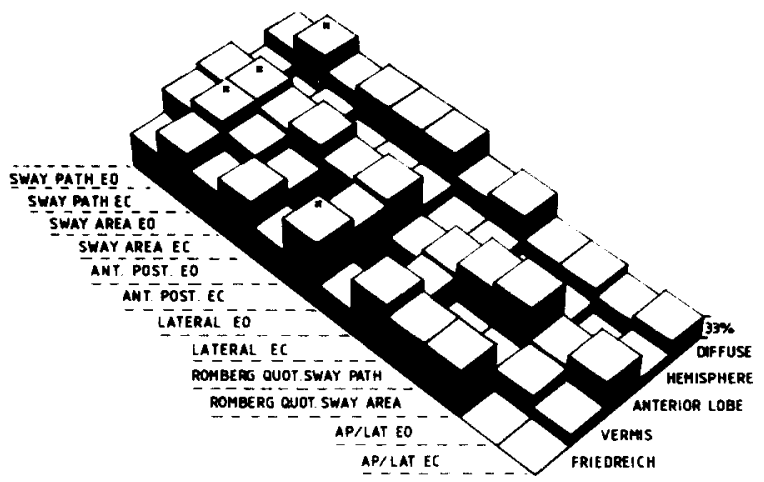

Fig. 2. Frequency of pathological results with different sway parameters (from left to right) across the 5 patient groups (from the foreground to the background). Columns with a cross on the top indicate $100 \%$ pathology. 


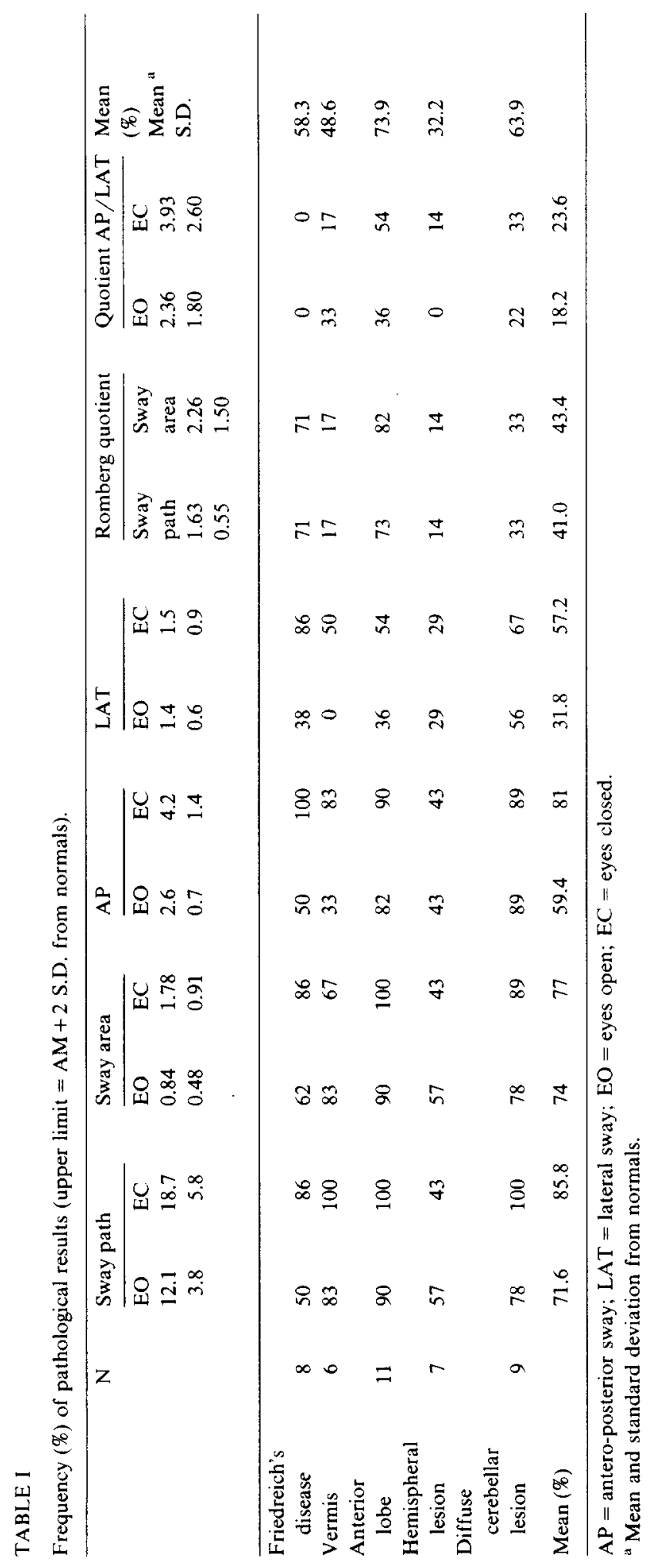


TABLE II

Analysis of variance for the results comparing the 5 groups of patients and normals.

\begin{tabular}{llll}
\hline $\begin{array}{l}\text { Measured } \\
\text { parameters }\end{array}$ & Eyes & $\begin{array}{l}F_{P<0.05}=2.38 \\
d f(5 / 55)\end{array}$ & $\begin{array}{l}\text { Multiple comparisons } \\
P<0.05\end{array}$ \\
\hline Sway path & Open & 3.74 & Ant. lobe $>$ norm \\
Sway path & Closed & 7.29 & Ant. lobe $>$ all others \\
Sway area & Open & 2.69 & - \\
Sway area & Closed & 3.10 & Ant. lobe $>$ norm \\
AP sway & Open & 4.04 & Ant. lobe $>$ norm \\
AP sway & Closed & 7.22 & Ant. lohe $>$ all others \\
LAT sway & Open & $1.85 \mathrm{n} . \mathrm{s}$. & - \\
LAT sway & Closed & 5.71 & Ant. lobe, Fried $>$ norm \\
AP/LAT quotient & Open & 2.62 & - \\
AP $/$ L.AT quotient & Closed & 2.26 & Ant. lobe $>$ vermis. \\
Romberg quotient & & & Hemisph. norm \\
sway path & & 6.32 & - \\
Romberg quotient & & 2.90 &
\end{tabular}
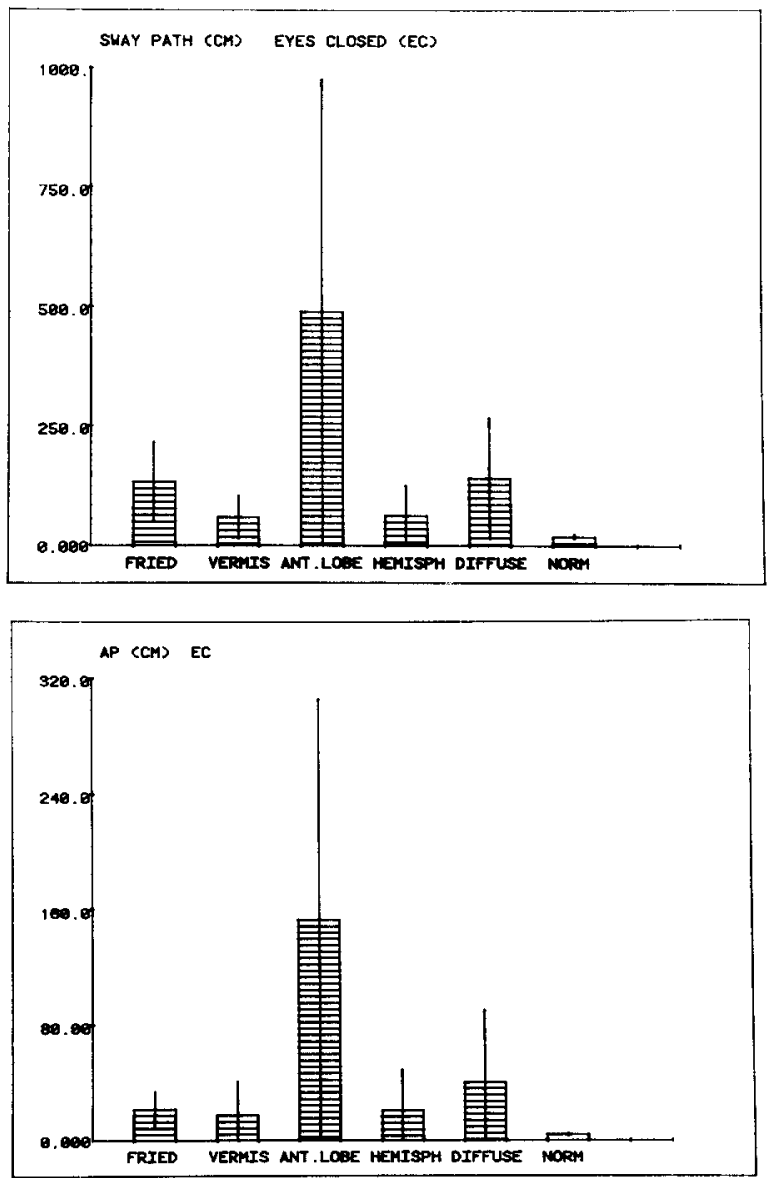

in these two groups. With lesions of the lower vermis and the cerebellar hemispheres the visual stabilization played a minor role.

Table II shows the results of an analysis of variance and of multiple comparisons. Despite the fact that $F$ values showed a significant difference between the patient groups (except for the lateral sway component with open eyes) only the patients with atrophy of the anterior lobe could be clearly differentiated from the others. This effect was most clearly visible in the sway path and the antero-posterior sway component with closed eyes (Fig. 3). Patients with Friedreich's ataxia who showed also an increased sway path and sway area could be differentiated from those with anterior lobe atrophy by the fact that their AP/LAT quotient was lower than that of normals, indicating a stronger lateral sway component.

Fig. 3. Means and standard deviations of the sway path $(\mathrm{cm}$. upper part) and the antero-posterior sway components (AP. lower part) recorded with the eyes closed from the 5 groups of patients. Patients with Friedreich's ataxia (FRIED), lesions of the cerebellar vermis (VERMIS), the anterior lobe (ANT. LOBE), the cerebellar hemispheres (HEMISPH), diffuse cerebellar atrophies (DIFFUSE) compared to normals (NORM). Both parameters clearly differentiate patients with the anterior lobe disease. 
TABLE III

Analysis of variance of root mean squares. Five patient groups and normals.

\begin{tabular}{lll}
\hline Parameter & $\begin{array}{l}F_{P<0.05}=2.38 \\
d f=5 / 55\end{array}$ & Multiple comparisons \\
\hline CFP AP EO & 3.54 & - \\
CFP AP EC & 6.96 & Ant. lobe $>$ vermis, \\
& & Hemisph, norm \\
CFP LAT EO & 3.26 & - \\
CFP LAT EC & 7.92 & Fried $>$ verm, hemisph. \\
& & Norm $/$ ant. lobe $>$ norm \\
\hline
\end{tabular}

$\mathrm{CFP}=$ center of foot pressure; $E O=$ eyes open; $E C=$ eyes closed.
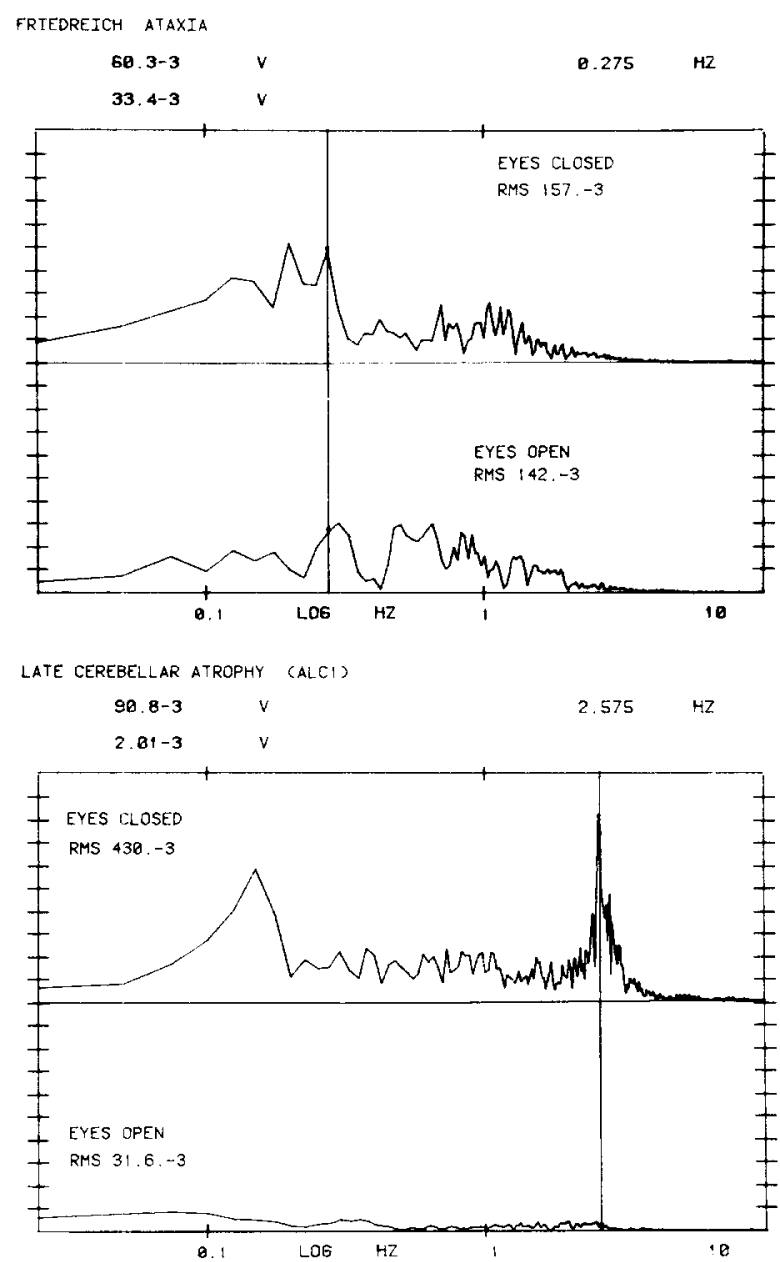

\section{(c) Results of Fourier analysis}

The root mean squares of the Fourier spectra of the displacement of the center of foot pressure give a frequency independent global measure of postural instability (Kapteyn and Bles 1976). Table III shows the results of an analysis of variance for the 5 patient groups and the normals. It reveals significant $F$ values for all measured parameters. The multiple comparisons indicate that with open eyes no patient group produced parameters that exceeded those of normals. With closed eyes, patients with Friedreich's ataxia and anterior lobe atrophy could be differentiated from those with lower vermal lesions and those with diseases which affected the cerebellar hemispheres. The last two frequently displayed root mean squares which were within the range of normality. Again, patients with Friedreich's ataxia had the highest CFP root mean squares when the lateral component was computed. The AP root mean squares were highest in patients with anterior lobe atrophy. The most prominent peak of the frequency spectrum of CFP movement was always within the range of 0.1-1 $\mathrm{Hz}$ for patients with Friedreich's ataxia and between 2 and $4 \mathrm{~Hz}$ (mainly around $3 \mathrm{~Hz}$ ) for the patients with anterior lobe lesions (Fig. 4).

\section{Discussion}

A parametric comparison of sway path and sway area in normals with the data from other authors is impossible since the recording techniques and methods of data processing differ too much. Relative measurements, such as the differences between closed and open eyes or the ratio

Fig. 4. Comparison of Fourier power spectra from a patient with Friedreich's ataxia (upper part) and a patient with atrophy of the anterior lobe. The main frequency components in the patient with Friedreich's ataxia are between 0.1 and $1 \mathrm{~Hz}$. The second patient shows the pathognomonic $2.6 \mathrm{~Hz}$ peak with closed eyes but not with open eyes. The root mean squares of

- sway (upper limit $=38.00$ ) are also normal with open eyes. The scaling on the ordinate indicates $100 \mathrm{mV} / \mathrm{steps}$. The vertical line indicates the measured frequency $(0.275$ and $2.575 \mathrm{~Hz})$. The numbers at the top of the figures indicate the power at this frequency $(\mathrm{mV})$. 
of antero-posterior to lateral sway are comparable. The stabilizing effect of vision on upright human stance has been recognized since the observations of Romberg (1853). The 'Romberg quotient' for the sway path of the CFP in normals, found to be 1.63 in this study, ranged between 1.26 and 1.7 according to recalculation from original data in the literature (Edwards 1946; Gurfinkel and Elner 1973; Njiokiktjien and Van Parys 1976; Terekhov 1976; Dornan et al. 1978; Taguchi et al. 1978; Hufschmidt et al. 1980). The predominance of the antero-posterior sway over lateral sway is stronger using our method than reported in the literature (Edwards 1946; Kapteyn 1972; Dichgans et al. 1976; Seidel et al. 1978; Okubo et al. 1979; Hufschmidt et al. 1980). This is because our subjects stood with their feet $4 \mathrm{~cm}$ apart, a position which diminishes lateral sway.

Despite large inter- and intraindividual variation, posturography helps to differentiate between different lesions of the cerebellum (Table IV). Our study not only gives a description of specific sway patterns in different cerebellar diseases, but also demonstrates that different sway parameters are important for the topical diagnosis of a cerebellar lesion. These results are not purely descriptive, but allow the differentiation between different cerebellar diseases with a statistical certainty. Patients

TABLE IV

Flow diagram for the topical diagnosis of ataxia of stance.

A. Sway parameters normal or less than $30 \%$ pathological

\section{7}

Hemispheral cerebellar lesion

B. Sway parameters more than $30 \%$ pathological

$\begin{aligned} & \text { Poor visual stabilization } \\ & \text { (low Romberg quotient) }\end{aligned}$
$\begin{aligned} & \text { Lesion of the } \\ & \text { vestibulo-cerebellum }\end{aligned}$
$\begin{aligned} & \text { Antero-posterior sway } \\ & \text { (high AP/LAT) }\end{aligned}$
$\begin{aligned} & \text { Omigh Romberg quotient) } \\ & \text { (low AP } / \mathrm{LAT} \text { ) }\end{aligned}$
Anterior lobe atrophy

with Friedreich's ataxia showed a clear increase of postural instability with a high proportion of visual stabilization, as indicated by the high Romberg quotient of sway path and sway area. The most prominent peak of the Fourier spectrum of AP and lateral sway in patients with Friedreich's ataxia was generally observed between 0.2 and 0.7 $\mathrm{Hz}$ and again around $1 \mathrm{~Hz}$. This is reminiscent of the peaks observed in patients with tabes dorsalis and normals with ischemic deafferentation of the legs (Aggashyan et al. 1973; Mauritz and Dietz 1980; Diener et al. 1983) and proves the involvement of the afferent spinal pathways in this disease. Patients with Friedreich's ataxia never exhibited a high frequency CFP tremor peak (2 4 $\mathrm{Hz}$ ) as was observed in the anterior lobe patient with eyes closed (Dichgans et al. 1976; Silfverskiöld 1977a, b; Mauritz et al. 1979, 1981). Since the majority of our patients suffered from an incipient atrophy, spontaneous tremor of stance was recorded in only 1 patient with eyes open and 6 of the 11 with eyes closed. Passive displacement of the platform around the ankle joint, however, invariably provoked $3 \mathrm{~Hz}$ tremor in these patients (Mauritz et al. 1981; Dichgans et al. 1983). The tremor, possibly provoked by pushing against the chest, is frequently visible to the examining clinician.

Patients with purely hemispheral lesions could not be differentiated from normals by our methods (Mauritz et al. 1979; Dichgans and Mauritz 1982). This result supports the assumption that the neocerebellum acts in the initiation and control of voluntary movements of arms and legs and less in postural reactions (Brooks 1979; Brooks and Thach 1981). Patients with diffuse cerebellar lesions, as expected, showed increased sway parameters, but no specific pattern of pathological sway. The visual stabilization of posture seems to depend on the functional integrity of the vestibulo-cerebellum (the known projections to the flocculus?) and possibly other connections to the cerebellar hemispheres. This is indicated by the relatively poor visual stabilization in these two groups of patients. Visual stabilization seems not to be affected by anterior lobe lesions and in patients with Friedreich's ataxia.

In patients in whom the differentiation is im- 
possible by means of posturography, dynamic tests such as tilting the platform sinusoidally around the ankle joint, thereby injecting a low frequency disturbance, or suddenly displacing the platform and measuring the reflex responses in leg muscles supply valuable additional information (Dichgans et al. 1983).

\section{Summary}

Posturography was performed in 41 patients with cerebellar diseases by means of a force measuring platform using an on-line computer program which calculated sway path, sway area, antero-posterior and lateral sway components and the amount of visual stabilization. Postural ataxia was quantitatively studied in 8 patients with spinal ataxia (Friedreich's), 6 patients with vestibulocerebellar lesions, 11 patients with anterior lobe atrophy, 7 patients with hemispheral cerebellar lesions, and 9 patients with a disease affecting all parts of the cerebellum. Patients with lesions of the cerebellar hemispheres could not be separated from normals by means of posturography. Lesions of the spino-cerebellar afferents (Friedreich's ataxia) caused an omnidirectional low frequency sway with preserved visual stabilization. Patients with anterior lobe atrophy showed a predominant antero-posterior sway, often with a spontaneous high frequency body tremor around $3 \mathrm{~Hz}$. Vestibulo-cerebellar lesions exhibited omnidirectional low frequency sway poorly stabilized by vision. Quantitative posturography helps to localize cerebellar lesions and allows for quantitative follow-up studies of cerebellar diseases.

\section{Résumé}

Quantification des oscillations posturales chez des sujets normaux et des patients cérébelleux

On a soumis à l'analyse posturographique 41 patients atteints de maladies du cervelet, ceci à l'aide d'une plateforme mesurant les forces, avec programme de calcul en ligne de la direction de l'oscillation, de sa surface, de ses composantes antéro-postérieure et latérale, et du degré de stabilisation visuelle.

L'ataxie posturale a été étudiée quantitativement chez 8 patients avec ataxie spinale (de Friedreich), 6 patients avec lésion vestibulocérébelleuse, 11 avec une atrophie du lobe antérieur, 7 avec lésion des hémisphères cérébelleux et 9 avec une affection touchant toutes les parties du cervelet. Les sujets atteints aux hémisphères cérébelleux n'ont pas, avec la méthode posturographique, pu être séparés des normaux. L'ataxie de Friedreich était accompagnée d'oscillations à fréquence lente, dans toutes les directions. mais avec maintien de la stabilisation visuelle. Les patients avec atrophie du lobe antérieur montraient des oscillations avec prédominance antéropostérieure, souvent accompagnées de tremblements corporels à fréquence élevée (autour de 3 $\mathrm{Hz}$ ). Les lésions vestibulo-cérébelleuses ont entraîné des oscillations omnidirectionnelles à basse fréquence, très mal stabilisées par la vision.

La posturographie quantitative aide ainsi à localiser les lésions du cervelet et permet de suivre quantitativement l'évolution des affections cérébelleuses.

\section{References}

Adams, R.A. Nutritional cerebellar degeneration. In: P.J. Vinken and G.W. Bruyn (Eds.), Handbook of Clinical Neurology. North-Holland Publ. Co., Amsterdam, 1976: $271-284$.

Aggashyan, R.V., Gurfinkel, V.S., Mamasakhilisov, G.V. and Elner, A.M. Changes in spectral and correlation characteristics of human stabilograms at muscle afferentation disturbance. Agressologie, 1973, 14: 5-9.

Brooks, V.B. Control of intended limb movements by the lateral and intermediate cerebellum. In: H. Asanuma and J.V. Wilson (Eds.), Integration in the Nervous System. Igaku-Shoin, Tokyo, 1979: 321-357.

Brooks, V.B. and Thach, W.T. Cerebellar control of posture and movement. In: V.B. Brooks (Ed.), Handbook of Physiology. The Nervous System, Vol. II. Amer. Physiol. Soc. Bethesda, MD, 1981: 877-946.

Dichgans, J. and Mauritz, K.H. The pathophysiology of postural imbalance in cerebellar patients. In: V. Honrubia and M.A. Brazier (Eds.), Nystagmus and Vertigo: Clinical Approaches to the Patient with Dizziness. Academic Press. New York, 1982: 179-189.

Dichgans, J., Mauritz, K.H., Allum, J.H. and Brandt, T. Pos- 
tural sway in normals and atactic patients: analysis of the stabilizing and destabilizing effects of vision. Agressologie, 1976, 17: 15-24.

Dichgans, J., Diener, H.C. and Mauritz, K.H. What distinguishes the different kinds of postural ataxias in patients with cerebellar diseases. Adv. Oto-Rhino-Laryng., 1983, 30: in press.

Diener, H.C., Dichgans, J., Guschlbauer, B. and Mau, H. The significance of proprioception on postural stabilization as assessed by ischemia. Brain Res., 1983, in press.

Dornan, J., Fernie, G.R. and Holliday, P.J. Visual input: its importance in the control of postural sway. Arch. phys. Med. Rehab., 1978, 59: 586-591.

Edwards, A.S. Body sway ar,d vision. J. exp. Psychol., 1946, 36: 526-535.

Gurfinkel, V.S. and Elner, A.M. On two types of statics disturbances in patients with local lesions of the brain. Agressologie, 1973, 14: 65-72.

Hufschmidt, A., Dichgans, J., Mauritz, K.H. and Hufschmidt, $M$. Some methods and parameters of body sway quantification and their neurological application. Arch. Psychiat. Nervenkr., 1980, 228: 135-150.

Kapteyn, T.S. Data processing of posturographic curves. Agressologie, 1972, 13 (Suppl. B): 29-33.

Kapteyn, T.S. and Bles, W. Effects of optic and vestibular stimuli on the stabilograms of patients with dizziness complaints. Agressologie, 1976, 17: 25-29.

Mancall, E.L. Late (acquired) cortical cerebellar atrophy. In: P.J. Vinken and G.W. Bruyn (Eds.), Handbook of Clinical Neurology, Vol. 21. North-Holland Publ., Amsterdam, 1975: 477-508.

Marie, P., Foix, C. et Alajouanine, T. De l'atrophie cérébelleuse tardive à prédominance corticale (atrophie parenchymateuse primitive des lamelles du cervelet, atrophie paléocérébelleuse primitive). Rev. neurol., 1922, 29: 849-885, $1082-1111$.

Mauritz, K.H. and Dietz, V. Characteristics of postural insta- bility by ischemic blocking of leg afferents. Exp. Brain Res., 1980, 38: 117-119.

Mauritz, K.H., Dichgans, J. and Hufschmidt, A. Quantitative analysis of stance in late cortical cerebellar atrophy of the anterior lobe and other forms of cerebellar ataxia. Brain, 1979, 102: 461-482.

Mauritz, K.H., Schmitt, C. and Dichgans, J. Delayed and enhanced long latency reflexes as the possible cause of postural tremor in late cerebellar atrophy. Brain. 1981. 104: 97-116.

Njiokiktjien, C.J. and Van Parys, J.A.P. Romberg's sign expressed in a quotient. II. Pathology. Agressologie. 1976. 17D: $19-24$

Okubo, J., Watanabe, I., Takeya, T. and Baron. J.B. Influence of foot position and visual field condition in the examination for equilibrium function and sway of the center of gravity in normal persons. Agressologie, 1979. 20: 127-132.

Romberg, M.H. Lehrbuch der Nervenkrankheiten des Menschen. Berlin, 1853.

Seidel, H., Braeuer, D., Bastek, R. and Issel, I. On the reproducibility and changes of stabilograms in investigations with long-term performance. Agressologie, 1978, 19: 93-95.

Silfverskiöld, B.P. Cortical cerebellar degeneration associated with a specific disorder of standing and locomotion. Acta neurol. scand., 1977a, 55: 257-272.

Silfverskiöld, B.P. A $3 \mathrm{c} / \mathrm{sec}$ leg tremor in a "cerebellar syndrome'. Acta neurol. scand., 1977b. 55: 385-393.

Taguchi, K., Iijima, M. and Suzuki, T. Computer calculation of movement of body's center of gravity. Acta oto-laryng. (Stockh.), 1978, 85: 420-425.

Terekhov, Y. Stabilometry as a diagnostic tool in clinical medicine. Canad. med. Ass. J., 1976, 115: 631-633.

Van Parys. J.A.P. and Njiokiktjien, C.J. Romberg's sign expressed in a quotient. Agressologie, 1976, 17B: 95-100.

Victor, M., Adams, R.D. and Mancall, E.L. A restricted form of cerebellar cortical degeneration occurring in alcoholic patients. Arch. Neurol. (Chic.), 1959, 1: 579-688. 